\title{
Acknowledgment to referees
}

Published online: 9 January 2020

(C) Springer-Verlag GmbH Germany, part of Springer Nature 2020

Dear reviewers, thank you for all your efforts!

In 2019, the number of manuscripts submitted to the European Journal of Clinical Pharmacology has increased to about 800 . Unbiased evaluation of the quality of submissions would be impossible without you, the honorary peer scientist volunteering to dedicate their time and expertise to read, assess and comment each manuscript. You did so in the best interest of authors, of the scientific community, and of the Journal. Beyond assessment, your comments often contributed to substantial improvement of manuscripts to make them publishable at all. This way, you even donated your knowledge to support your very own competitors.

Our editorial team is well aware that making time available for carrying out this important task is becoming increasingly difficult, as along with the increasing number of submissions, the number of other types of evaluations, of grant applications, and the general workload continues to increase for all of you. We also hope that you don't find it too frustrating if your recommendations are overruled by one of the Managing Editors - but occasionally, reviews are conflicting, and it is not always possible to make a decision to which all involved parties would agree. For all these reasons, we appreciate your efforts and your support very much, and would like to thank you wholeheartedly!

Unfortunately, we are unable to publish the names of individual reviewers because of the European data protection rules and personal data must not be disclosed. For those reviewers who want to have their work acknowledged with a Reviewer Certificate of Recognition, please get in touch with the Editorin-Chief.

We are looking forward to continue this successful collaboration with you - beyond being thankful, it is a mere pleasure to see all the brilliant peers at work!

Rune Dahlqvist

Uwe Fuhr

Emilio J. Sanz

David J.P. Williams

Markus Zeitlinger

Hans Detlef Klüber (Springer Nature)

Ingrid Fischer (Springer Nature) 